\title{
A method to calculate reasonable water injection rate for $M$ oilfield
}

\author{
Kaichun $\mathrm{Yu}^{1,2} \cdot$ Kuang $\mathrm{Li}^{3} \cdot$ Qianru $\mathrm{Li}^{3} \cdot$ Keman $\mathrm{Li}^{3} \cdot$ Feng $\mathrm{Yang}^{3}$
}

Received: 5 December 2016/Accepted: 14 May 2017/Published online: 26 May 2017

(C) The Author(s) 2017. This article is an open access publication

\begin{abstract}
In recent years, $M$ oilfield has entered into high water cut stage. Two main problems are imposed in the process of development including sharp water cut rising rate and rapid oil production decline. These problems are difficult to solve, which may bring other problems. In order to slow down production decline rate and control the rising rate of water cut, it is necessary to control water injection rate. However, oil production rate can be affected if water injection rate is too low to provide enough water volume for maintaining reservoir pressure. A method to calculate reasonable injection-production ratio and predict water cut is provided in this paper. Its main mechanism is to resolve above contradictions by calculating reasonable water injection rate. Firstly, an equation to calculate reasonable injection-production ratio is deduced by material balance equation. It considers several parameters including rate of pressure recovery, water cut and other production indexes. Secondly, reasonable oil production rates and water cut of future 10 years are predicted. Oil production is predicted by the law of production decline, and water cut is predicted by regression equation of water drive characteristic curve. Lastly, reasonable water injection rates of next 10 years are calculated through predicted injection-production ratios and liquid production rates. Taking $\mathbf{M}$ oilfield as an example, this paper presents a method to determine
\end{abstract}

Kaichun $\mathrm{Yu}$

wenbinliu2016@163.com

1 Department of Earth Sciences, Zhejiang University, Hangzhou 310027, China

2 The Fifth Oil Production Factory, Daqing Oilfield Company, Daqing 163000, China

3 College of Petroleum Engineering, Northeast Petroleum University, Daqing 163318, China reasonable water injection rate of multilayer sandstone water drive reservoir.

Keywords Reasonable water injection rate $\cdot$ Reasonable reservoir pressure - Material balance equation - Anticline multilayer sandstone water drive reservoir

\section{Introduction}

For the development of multilayer sandstone heterogeneous water drive reservoirs, because of the inhomogeneous advance of injected water in vertical and horizontal directions, dominant channels of water flow in reservoir are formed ( $\mathrm{Li}$ 2003; Wagn et al. 2016; Sommerauer and Zerbst 2007). Therefore, there are a series of problems in extra high water cut stage including sharp production decline and rapid water cut rising (Hou 2014; Chen 1986; Rehman et al. 2015). There will be remaining oil enrichment in unswept region if fluid advantage channels are created, which could affect the final recovery. A lot of research has been performed on this problem. The key to solve this problem is ascertaining reasonable injectionproduction ratio (Li et al. 2015; Orozco and Aguilera 2017; Zhao 2013; Ballin et al. 2012). Shangguan put forward an optimization model about reasonable injection allocation. It provides a theoretical basis for the establishment of oilfield adjustment scheme (Shangguan et al. 2003; Shan et al. 2013; Paige et al. 1995). Luo investigated the quantitative relationship among injection-production ratio, reservoir pressure, liquid production and water cut through material balance equation and water drive characteristic curve (Luo and Xu 1999; Wang 2013; Palsson et al. 2003; Olu et al. 2014). Gao et al. (2000) and Chen (1985) introduced the application of water drive characteristic 
curve in predicting oilfield development indexes. Cui calculated water influx rate of edge water reservoir by material balance equation. Based on water influx rate, relational formula between formational pressure recovery rate and injection-production ratio is deduced. It could be used to predict reasonable injection-production ratio (Cui et al. 2010; Zhu et al. 2015; Yu et al. 2010). In 1967, J. L. Anyhony (Buckwalter 1951; Qixin et al. 1997; Frederick and Kelkar 2005), an American scholar, studied the best economic water injection rate and corresponding water injection pressure according to volume distribution of water flooding. In 1991, P. M. Cattpob (Gulick et al. 1998) analyzed the influence of liquid production rate and water injection on oil production in different development stages of oil field by statistical analysis. Based on material balance equation and water drive characteristic curve, a lot of research has been performed on the law of oil field water injection in recent years (Bashiri and Kasiri 2011; Chambers et al. 1980; Dong et al. 1999). These research findings have an important guiding role in research of reasonable water injection rate.

In this study, reasonable development indexes of $\mathrm{M}$ oilfield are predicted. Its main objective is to control these indexes at a proper range, which could handle with the contradiction between reservoir pressure and water cut for multilayer sandstone water drive reservoir.

\section{General situation of $M$ oilfield}

\section{Geological conditions}

$\mathrm{M}$ oilfield is an anticline multilayer sandstone water drive reservoir. Oil-water distribution is controlled by anticline. The buried depth of this reservoir is at the range of 890-1190 m. Hydrodynamic system of each layer is the same. Each layer has a unified oil/gas and oil/water interface. Oil-containing area is $7.8 \mathrm{~km}^{2}$. Original oil in place is $2418.8 \times 10^{4} \mathrm{t}$.

Different depositional environments caused serious heterogeneity in this oilfield. Interlayer heterogeneity is mainly embodied as big differences among layers in vertical direction. Areal heterogeneity is mainly embodied as unequal water flooding area. In layer heterogeneity is mainly embodied as remaining oil enrichment and fluid dominant channels.

\section{Development conditions}

\section{Development history}

The basic well pattern was put into production in 1971, the water flooding regime of which is four-spot pattern. Initial well spacing was $400 \mathrm{~m}$. Sa \& Pu oil layers were developed by a set of layer system. Primary well pattern infilling was started in 1988 and ended in 1990. Its water flooding regime remains four-spot pattern. Secondary well pattern infilling was implemented in 1997. Its main objective is to develop two types of bad reserves. The first type is the thin and bad layers, the effective thickness of which is less than $0.5 \mathrm{~m}$. The second type is the undeveloped reservoirs. Secondary well infilling adopted line water flooding. The well spacing was $346 \mathrm{~m}$. Tertiary well pattern infilling was implemented in 2007 in order to further improve the development effect of thin layer and undeveloped reservoir. Lines of oil wells were inserted into the existing well pattern. It is a zigzag shape. Some oil wells were converted into injection wells. The well spacing is $200 \mathrm{~m}$ (Table 1).

\section{Oilfield exploitation situation in 2014}

In 2014, there are 348 wells in the whole reservoir. The number of oil wells is 228. The number of water wells is 120. Well spacing density is 44.6 wells $/ \mathrm{km}^{2}$. Two hundred and ten oil wells were put into production. Liquid production rate is $5771 \mathrm{t} / \mathrm{d}$. Oil production rate is $320.8 \mathrm{t} / \mathrm{d}$. Comprehensive water cut is $94.38 \%$. Verify oil production rate is $12.05 \times 10^{4} \mathrm{t} / \mathrm{a}$. Annual water cut is $94.13 \%$. Cumulative oil production is $1046.4 \times 10^{4} \mathrm{t}$. Degree of reserve recovery is $43.26 \%$. One hundred and thirteen injection wells were put into production. Water injection rate is $7097 \mathrm{~m}^{3} / \mathrm{d}$. Cumulative water injection volume is $6815.53 \times 10^{4} \mathrm{~m}^{3}$. Cumulative injection-production ratio is 1.12 . Formation pressure is $10.24 \mathrm{MPa}$.

Overall, the target block has entered into the high water cut stage. Its degree of reserve recovery is high. The injection-production ratio and reservoir pressure were kept within a reasonable range. There is still some remaining oil tapping potential space.

\section{The method to predict reasonable injection- production ratio}

\section{Formula for calculating injection-production ratio}

In different water cut stages, the law of oil and water movement is different, and thus, the change trend of water cut rising rate is also different. To maintain oil production rate stable, it is necessary to change injection-production ratio with the progress of production. From two aspects of theory and experience, this paper analyzes the influence of different injection-production ratio on the rate of water cut and then determines the reasonable injection-production ratio.

Reservoir pressure could be restored and maintained by water injection. However, due to the different physical 
Table 1 Summary sheet of well pattern deployment for target block

\begin{tabular}{|c|c|c|c|c|c|c|c|c|}
\hline Well pattern & Developing objects & $\begin{array}{l}\text { Well } \\
\text { pattern }\end{array}$ & $\begin{array}{l}\text { Well } \\
\text { spacing } \\
(\mathrm{m})\end{array}$ & $\begin{array}{l}\text { Perforating } \\
\text { thickness (m) }\end{array}$ & $\begin{array}{l}\text { Effective } \\
\text { thickness } \\
\text { (m) }\end{array}$ & $\begin{array}{l}\text { Number of } \\
\text { oil wells }\end{array}$ & $\begin{array}{l}\text { Number of } \\
\text { water wells }\end{array}$ & $\begin{array}{l}\text { Well spacing } \\
\text { density (wells/ } \\
\mathrm{km}^{2} \text { ) }\end{array}$ \\
\hline Basic wells & $\begin{array}{l}\text { Commingled production of } \mathrm{Sa} \\
\text { and } \mathrm{Pu}\end{array}$ & $\begin{array}{l}\text { Four- } \\
\text { spot }\end{array}$ & 400 & 38.1 & 19.7 & 42 & 14 & 7.2 \\
\hline $\begin{array}{l}\text { Primary well } \\
\text { pattern } \\
\text { infilling }\end{array}$ & Non-main layers of $\mathrm{Sa}$ and $\mathrm{Pu}$ & $\begin{array}{r}\text { Four- } \\
\text { spot }\end{array}$ & 346 & 32.1 & 12.1 & 37 & 31 & 8.7 \\
\hline $\begin{array}{l}\text { Secondary well } \\
\text { pattern } \\
\text { infilling }\end{array}$ & $\begin{array}{l}\text { Thin layers of usable and } \\
\text { useless reserves of } \mathrm{Sa} \text { and } \\
\mathrm{Pu}\end{array}$ & Line & 346 & 27.5 & 8.0 & 13 & 69 & 10.5 \\
\hline $\begin{array}{l}\text { Tertiary well } \\
\text { pattern } \\
\text { infilling }\end{array}$ & $\begin{array}{l}\text { Thin layers of usable and } \\
\text { useless reserves of } \mathrm{Sa} \text { and } \\
\mathrm{Pu}\end{array}$ & Line & 200 & 24.2 & 5.7 & 136 & 9 & 18.6 \\
\hline Total & & & & 28.7 & 9.7 & 228 & 123 & 45.0 \\
\hline
\end{tabular}

properties of the blocks, to maintain a high level of pressure, the reasonable injection-production ratio is different for different blocks. The main factors affecting formation pressure include cumulative water production, cumulative oil production, cumulative water injection and compressibility and volume factors of rock, oil and water. According to the relationship between recovery rate of reservoir formation pressure and injection-production ratio studied by Cui et al., the formula of calculating reasonable injectionproduction ratio is derived in this paper.

The following formula is derived from material balance equation.

$W_{\mathrm{i}}-N_{\mathrm{p}} B_{\mathrm{o}} / \rho_{\mathrm{o}}-W_{\mathrm{p}}=N C_{\mathrm{e}} B_{\mathrm{oi}} \Delta P$

where $W_{\mathrm{p}}$ is the cumulative water production. $N_{\mathrm{p}}$ is the cumulative oil production. $W_{\mathrm{i}}$ is the cumulative water injection volume. $B_{\mathrm{o}}$ is the volume factor of oil. $B_{\mathrm{oi}}$ is the original volume factor of oil. $N$ is the original oil in place. $C_{\mathrm{e}}$ is the comprehensive compressibility. $\Delta P$ is the pressure drawdown of this oilfield. $\rho_{\mathrm{o}}$ is the oil density.

Derivates of variables of formula (1) with respect to time are calculated. Derivate of volume factor with respect to time is ignored. This equation can be transformed to the following formula combining the expression of injectionproduction ratio.

$\frac{\mathrm{d}(\Delta p)}{\mathrm{dt}}=\frac{Q_{\mathrm{l}}(\mathrm{IPR}-1)\left[\left(1-f_{\mathrm{w}}\right) B_{\mathrm{o}} / \rho_{\mathrm{o}}+f_{\mathrm{w}}\right]}{N C_{\mathrm{e}} B_{\mathrm{oi}}}$

where $f_{\mathrm{w}}$ is the water cut. $Q_{1}$ is the stable production liquid yield. $t$ is the production time. IPR is the injection-production ratio.

Liquid production rates, water cuts, original oil in place and physical properties of $\mathrm{M}$ oilfield are put into above formula. The injection-production ratio corresponding to different pressure change rates can be obtained. It can be seen from the above formula that the pressure change rate increases with the increase in injection-production ratio.
The $N C_{\mathrm{e}} B_{\mathrm{oi}}$ is replaced with $K$. Formula (2) is transformed as follows:

$$
\mathrm{IPR}=K \times \frac{\mathrm{d}(\Delta p) / \mathrm{d} t}{Q_{1}\left[\left(1-f_{\mathrm{w}}\right) B_{\mathrm{o}} / \rho_{\mathrm{o}}+f_{\mathrm{w}}\right]}+1
$$

Formula (3) is an equation to calculate reasonable injection-production ratio. It includes some parameters including pressure recovery rate, liquid production, volume factor of oil, water cut, rock compressibility and original oil in place. In this reservoir, volume factor of oil is 1.118 and oil relative density is 0.864 .

$\Delta P$ reflects the goal of maintaining the level of formation pressure, $f_{\mathrm{W}}$ reflects the goal of controlling the rising rate of water cut. So the injection-production ratio is reasonable, and contradiction between formation pressure and water cut rising can be solved.

\section{The method to calculate " $K$ " value}

Injection-production ratio data of $\mathrm{M}$ oilfield are set as vertical coordinate. $\frac{\mathrm{d}(\Delta p) / \mathrm{d} t}{Q_{1}\left[\left(1-f_{\mathrm{w}}\right) B_{\mathrm{o}} / \rho_{\mathrm{o}}+f_{\mathrm{w}}\right]}$ is set as horizontal coordinate. The relationship curve between the two variables is drawn, and the slope of the curve is determined by the regression equation, which is the $K$ value.

Liquid production rate, water cut, pressure recovery rate and injection-production ratio data of this reservoir from 2004 to 2014 are shown in the following table.

According to the material balance equation, the liquid production of the last 10 years was taken as the stable liquid production $Q_{1}$. Drawdown pressure is adjusted in the range of -0.5 to $+0.5 \mathrm{MPa}$. Result shows that water cut rising rate will be maintained below $0.15 \%$ if average pressure recovery rate is $-0.41 \mathrm{MPa}$. There is a linear correlation between injection-production ratios and $\frac{\mathrm{d}(\Delta p) / \mathrm{d} t}{\left.\left.1-f_{\mathrm{w}}\right) B_{\mathrm{o}} / \rho_{\mathrm{o}}+f_{\mathrm{w}}\right]}$ of this oilfield. Regression line is shown as follows. 
Table 2 Production data of $\mathrm{M}$ oilfield

\begin{tabular}{lllll}
\hline Year & $\begin{array}{l}\text { Liquid production } \\
\text { rate }\left(\times 10^{4} \mathrm{~m}^{3} / \mathrm{a}\right)\end{array}$ & Water cut $(\%)$ & $\begin{array}{l}\text { Pressure recovery } \\
\text { rate (MPa) }\end{array}$ & $\begin{array}{l}\text { Actual injection-production } \\
\text { ratio }\end{array}$ \\
\hline 2004 & 160.825 & 91.333 & 1.845 & 1.283 \\
2005 & 155.891 & 91.791 & 3.973 & 1.184 \\
2006 & 150.837 & 92.092 & -0.879 & 1.261 \\
2007 & 167.347 & 91.386 & -0.993 & 1.197 \\
2008 & 193.151 & 91.937 & -0.464 & 1.210 \\
2009 & 216.896 & 93.254 & -1.006 & 1.138 \\
2010 & 215.142 & 93.806 & -0.440 & 1.112 \\
2011 & 232.755 & 94.053 & -0.150 & 1.085 \\
2012 & 227.184 & 93.752 & 3.028 & 1.154 \\
2013 & 217.712 & 93.868 & -2.162 & 1.113 \\
\end{tabular}

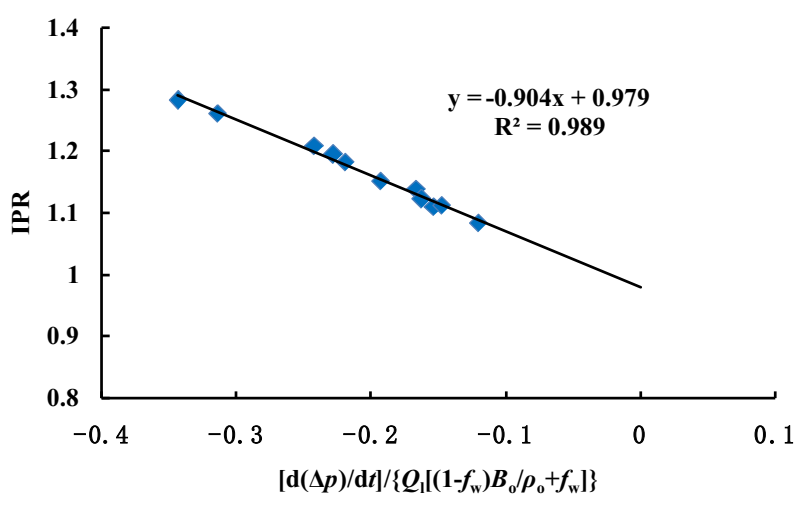

Fig. 1 Regression line between injection-production ratio data and $\mathrm{d}(\Delta p) / \mathrm{d} t$ $\frac{\mathrm{d}(\Delta p) / \mathrm{d} t}{Q_{1}\left[\left(1-f_{\mathrm{w}}\right) B_{\mathrm{o}} / \rho_{\mathrm{o}}+f_{\mathrm{w}}\right]}$

Assuming that the oilfield development conditions remain unchanged, the change law of the regression curve is also unchanged. If the production is maintained under the current conditions without any measures, the relationship between reasonable injection-production ratio and $\frac{\mathrm{d}(\Delta p) / \mathrm{d} t}{Q_{\mathrm{l}}\left[\left(1-f_{\mathrm{w}}\right) B_{\mathrm{o}} / \rho_{\mathrm{o}}+f_{\mathrm{w}}\right]}$ can be predicted by the above linear relationship.

The slope $K$ of regression line is equal to -0.904 . Its correlation factor $R^{2}$ is equal to 0.989 . Injection-production ratio can be predicted by the following equation.

$\mathrm{IPR}=-0.904 \times \frac{\mathrm{d}(\Delta p) / \mathrm{d} t}{Q_{1}\left[\left(1-f_{\mathrm{w}}\right) B_{\mathrm{o}} / \rho_{\mathrm{o}}+f_{\mathrm{w}}\right]}+1$

Table 2 and Fig. 1 show that injection-production ratio data were maintained about 1.17 from 2004 to 2014. Water content shows a rising trend year by year. The average value of pressure recovery rate can be obtained. Under the condition of constant pressure variation, the water cut decreases with the increase in injection-production ratio.

\section{The method to calculate oil production rate}

During the development of the target block, with the change of underground energy and the reduction in recoverable reserves, the oil production always shows a downward trend. This phenomenon could be quantified by oil production decline rate.

The expression of the decline rate is shown as follows:

$D=-\frac{\mathrm{d} q}{q \mathrm{~d} t}=k q^{n}$

where $D$ is the production decline rate, $\mathrm{a}^{-1} \cdot q$ is the oil production rate of oil and gas field in decline stage, $10^{6} \mathrm{t}$. The negative sign in this formula expresses that oil production rate decreases with the increase in development time.

Decline exponent $n$ is equal to $0 . d_{t}$ and the factor that only containing variable $t$ are put into one side of formula (5). $d_{\mathrm{q}}$ and the factor that only containing variable $q$ are put into another side. After that, integration of variables on the both sides of converted formula (5) with respect to time $t$ is calculated. Formula (6) is as follows:

$\ln \left(\frac{q_{\mathrm{i}}}{q_{t}}\right)=k t$

Initial production decline rate $D_{\mathrm{i}}$ calculated by formula (5) is equal to $k$. The value of $k$ is put into formula (6).

$D_{\mathrm{i}}=k$

$\ln \left(\frac{q_{\mathrm{i}}}{q_{t}}\right)=D_{\mathrm{i}} t$

Formula (8) can be transformed into the following form.

$q_{t}=q_{\mathrm{i}} \exp \left(-D_{\mathrm{i}} t\right)(n=0)$ 
The above formula is the relation of oil production with time, and there is an exponential function relation between them. Therefore, this decline law is called as exponential decline.

Logarithm of both sides of formula (9) is as follows:

$\lg q_{t}=\lg q_{\mathrm{i}}-D_{\mathrm{i}} \lg e t$

There is a linear relationship between logarithms of oil production $q_{t}$ and time $t$. Slope $K$ is equal to $-D_{\mathrm{i}} \lg e$. There will be a regression line in the Cartesian coordinates if logarithm of oil production rate data is drawn in coordinate paper. $D_{\mathrm{i}}$ can be calculated by the following formula.

$D_{\mathrm{i}}=-\frac{1}{\lg e} K=-2.3 K$

Cumulative oil production in production decline period is calculated by the following formula.

$N_{\mathrm{p}}=\int_{0}^{t} q_{t} \mathrm{~d} t$

Formula (9) is put into formula (12), and the integration with respect to time $t$ can be calculated by the following formula.

$N_{\mathrm{p}}=\frac{q_{\mathrm{i}}}{D_{\mathrm{i}}}\left[1-\exp \left(-D_{\mathrm{i}} t\right)\right]$

where $q_{\mathrm{i}}$ is the oil production rate at the beginning of production decline period, $10^{6}$ t. $q_{t}$ is the oil production rate in production declining period, $10^{6}$ t. $D_{\mathrm{i}}$ is the initial production decline rate. $N_{\mathrm{p}}$ is the cumulative oil production, $10^{6} \mathrm{t}$

Cumulative oil production at any time in production decline stage can be calculated by formula (13). Based on the basic data of the target block, the change curve of oil production over time of the whole block is drawn, and the curve is shown in Fig. 2.

Oil production rate of the whole reservoir has decreased regularly from 1998 to 2014. Assuming that the current production conditions remain unchanged, the linear regression curve is obtained by analyzing the production data after the tertiary well pattern infilling. The regression equation can be used to predict production decline law of the next ten years. Production decline law of this reservoir is shown in Fig. 3.

The above figure shows that slope is -0.013 . Then, production decline rate is equal to $0.031687 / a$.

Oil production rate and cumulative oil production can be calculated by formulas (9) and (13). Predicted results are listed in the following Table 3.

It can be seen from the above table that the annual oil production of the next ten years decreases year by year. The actual oil production in 2014 is $13.51 \times 10^{4} \mathrm{t} / \mathrm{d}$. By the end of 2024, the annual oil production is $9.67 \times 10^{4} \mathrm{t} /$

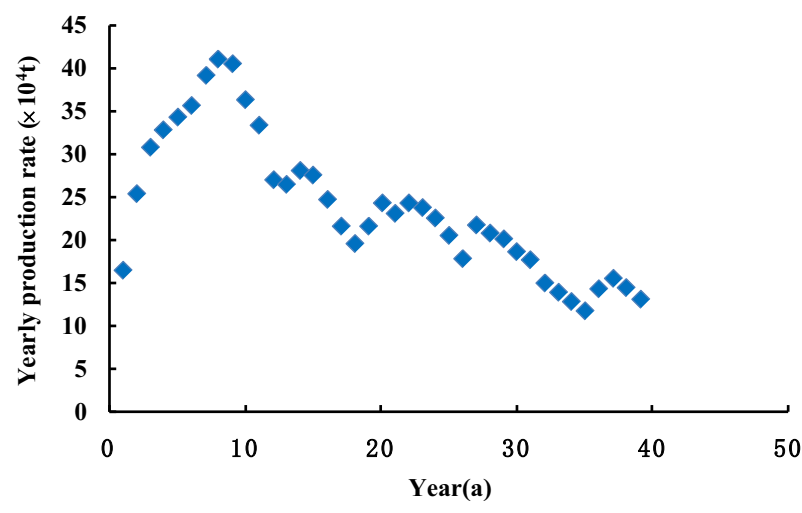

Fig. 2 Relation curve between oil production rates over time of $\mathrm{M}$ oilfield

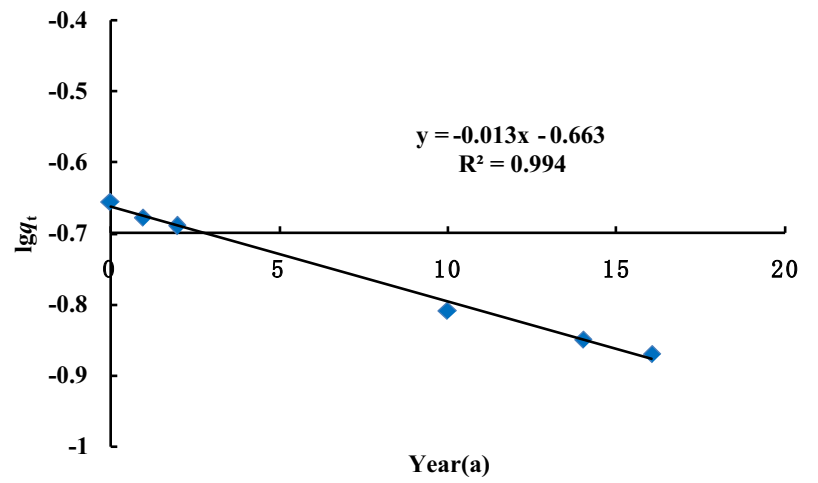

Fig. 3 Regression line of the production decline law in M oilfield

$\mathrm{d}$, and the average annual decrease in oil production is $0.384 \times 10^{4} \mathrm{t} / \mathrm{d}$. The cumulative oil production reaches $1111.013 \times 10^{4} \mathrm{t} / \mathrm{d}$ by the end of 2024 . The study area still has a certain potential tapping space.

\section{The method to predict water cut}

Water flooding characteristic curve could be applied to calculate most of the indexes of water flooding reservoir. It could be used to predict development indexes, calibrate recoverable original oil in place and evaluate development effects. According to Luo Chengjian's research on water drive characteristic curve and reasonable injection-production ratio, water cut and cumulative water production are predicted by water drive characteristic curve in this study.

In Cartesian coordinates, logarithms of cumulative water production are set as vertical coordinate, and cumulative oil production is set as horizontal coordinate. The relation curve between two variables is usually an approximate straight line. The basic expressions are shown as follows: 
Table 3 Results of predicted oil production rate and cumulative oil production of future 10 years

\begin{tabular}{lll}
\hline Year & $\begin{array}{l}\text { Predicted oil production } \\
\text { rate }\left(\times 10^{4} \mathrm{t} / \mathrm{a}\right)\end{array}$ & $\begin{array}{l}\text { Predicted cumulative } \\
\text { oil production }\left(\times 10^{4} \mathrm{t}\right)\end{array}$ \\
\hline 2015 & 12.862 & 1010.295 \\
2016 & 12.461 & 1022.955 \\
2017 & 12.073 & 1035.221 \\
2018 & 11.696 & 1047.104 \\
2019 & 11.331 & 1058.617 \\
2020 & 10.978 & 1069.771 \\
2021 & 10.635 & 1080.576 \\
2022 & 10.304 & 1091.045 \\
2023 & 9.982 & 1101.187 \\
2024 & 9.671 & 1111.013 \\
\hline
\end{tabular}

$\lg W_{\mathrm{p}}=B N_{\mathrm{p}}+A$

where $W_{\mathrm{p}}$ is the cumulative water production, $10^{6} \mathrm{t}$.

Relation curve between cumulative water production and cumulative oil production is as follows:

$N_{\mathrm{p}}=a\left(\lg W_{\mathrm{p}}-\lg b\right)$

(1) Prediction of cumulative water production Formula (15) is transformed into following formulas.

$W_{\mathrm{p}}=b \times 10^{\left(N_{\mathrm{p}} / a\right)}$

or

$W_{\mathrm{p}}=10^{\left(\lg b+N_{\mathrm{p}} / a\right)}$

Cumulative water production $W_{\mathrm{p}}$ can be calculated by formula (16) or (17) if cumulative oil production $N_{\mathrm{p}}$ is given.

According to the original data, the relationship curve between $\lg W \mathrm{p}$ and $\mathrm{Np}$ is shown as follows.

Assuming that the current production conditions remain unchanged, the water drive characteristic curve is obtained

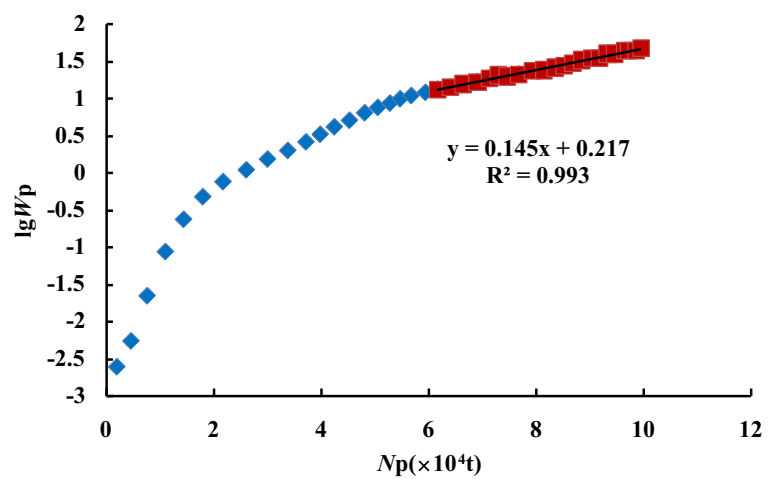

Fig. 4 Water flooding characteristic curve of $\mathrm{M}$ oilfield by analyzing the production data in recent years. Water drive characteristic curve can reflect the trend of future production. The regression equation can be used to predict water cut of the next 10 years (Fig. 4).

Line portion of water flooding characteristic curve is started in 1998 and ended in 2014. Slope B is equal to 0.145 , and intercept $A$ is equal to 0.217 . Relative parameters that are calculated by $A$ and $B$ are as follows: $a=\frac{1}{B}=6.8966, \quad b=10^{A}=1.6482$.

(2) Prediction of water cut

Derivates of variables on both sides of formula (17) with respect to time are as follows:

$\frac{\mathrm{d} N_{\mathrm{p}}}{\mathrm{d} t}=a \lg e \frac{1}{W_{\mathrm{p}}} \frac{\mathrm{d} W_{\mathrm{p}}}{\mathrm{d} t}$

$\frac{\mathrm{d} N_{\mathrm{p}}}{\mathrm{d} t}=q_{\mathrm{o}}$ and $\frac{\mathrm{d} W_{\mathrm{p}}}{\mathrm{d} t}=q_{\mathrm{w}}$ are put into formula (18). Water-oil ratio $F_{\text {wo }}$ is calculated by the following equation.

$F_{\text {wo }}=\frac{q_{\mathrm{w}}}{q_{\mathrm{o}}}=\frac{2.3 W_{\mathrm{p}}}{a}$

Water cut can be calculated by the following formula.

$f_{\mathrm{w}}=\frac{q_{\mathrm{w}}}{q_{\mathrm{w}}+q_{\mathrm{o}}}=\frac{1}{1+q_{\mathrm{o}} / q_{\mathrm{w}}}$

Formula (19) is put into formula (20), and the result is shown as follows:

$f_{\mathrm{w}}=\frac{2.3 W_{\mathrm{p}}}{a+2.3 W_{\mathrm{p}}}$

Cumulative water production, water production and water cut of future 10 years can be predicted by formulas (17) and (21). Results are given in the following Table 4.

It can be seen from the above table that the water cut rate of the next ten years increases year by year. The actual water cut rate in 2014 is $94.13 \%$. By the end of 2024 , the predicted water cut is $95.697 \%$, and the average annual increase in water cut rate is $0.1567 \%$, and the predicted cumulative water production reaches $6607.282 \times 10^{4} \mathrm{t} / \mathrm{d}$.

\section{The method to calculate reasonable water injection rate}

Liquid production rate and water cut calculated by water flooding characteristic curve of type "A" are put into formula (3). Reasonable injection-production ratio of $\mathrm{M}$ oilfield of future 10 years could be calculated. According to Shangguan' research on an optimization mathematical model about reasonable injection allocation, proper water injection rates of future 10 years can be calculated by formula (22). Results are shown as follows:

$Q_{\mathrm{i}}=\mathrm{IPR} \times\left(Q_{\mathrm{o}} \times B_{\mathrm{o}} / \rho_{\mathrm{o}}+Q_{\mathrm{w}}\right)$ 
Table 4 Predicted water cut of M oilfield

\begin{tabular}{llll}
\hline Year & $\begin{array}{l}\text { Predicted water } \\
\text { production rate } \\
\left(\times 10^{4} \text { t/a }\right)\end{array}$ & $\begin{array}{l}\text { Predicted cumulative } \\
\text { water production } \\
\left(\times 10^{4} \mathrm{t}\right)\end{array}$ & $\begin{array}{l}\text { Predicted } \\
\text { water cut } \\
(\%)\end{array}$ \\
\hline 2015 & 202.747 & 4705.491 & 94.062 \\
2016 & 205.126 & 4910.617 & 94.295 \\
2017 & 207.252 & 5117.869 & 94.514 \\
2018 & 209.126 & 5326.995 & 94.718 \\
2019 & 210.750 & 5537.745 & 94.909 \\
2020 & 212.125 & 5749.870 & 95.087 \\
2021 & 213.255 & 5963.125 & 95.254 \\
2022 & 214.144 & 6177.269 & 95.411 \\
2023 & 214.796 & 6392.065 & 95.559 \\
2024 & 215.217 & 6607.282 & 95.697 \\
\hline
\end{tabular}

Table 5 Predicted reasonable developing indexes for $\mathrm{M}$ oilfield

\begin{tabular}{lllll}
\hline Year & $\begin{array}{l}\text { Predicted liquid } \\
\text { production rate } \\
\left(\times 10^{4} \text { t/a }\right)\end{array}$ & $\begin{array}{l}\text { Predicted } \\
\text { water cut } \\
(\%)\end{array}$ & $\begin{array}{l}\text { Reasonable } \\
\text { injection- } \\
\text { production } \\
\text { ratio }\end{array}$ & $\begin{array}{l}\text { Predicted water } \\
\text { injection rate } \\
\left(\times 10^{4} \mathrm{~m}^{3} / \mathrm{a}\right)\end{array}$ \\
\hline 2015 & 215.609 & 94.062 & 1.1528 & 253.144 \\
2016 & 217.587 & 94.295 & 1.1515 & 254.996 \\
2017 & 219.325 & 94.514 & 1.1504 & 256.613 \\
2018 & 220.822 & 94.718 & 1.1494 & 257.993 \\
2019 & 222.081 & 94.909 & 1.1487 & 259.139 \\
2020 & 223.103 & 95.087 & 1.1481 & 260.050 \\
2021 & 223.890 & 95.254 & 1.1476 & 260.732 \\
2022 & 224.447 & 95.411 & 1.1473 & 261.185 \\
2023 & 224.778 & 95.559 & 1.1472 & 261.416 \\
2024 & 224.888 & 95.697 & 1.1472 & 261.429 \\
\hline
\end{tabular}

According to the formula of reasonable injection-production ratio, the reasonable injection-production ratio and reasonable water injection rate of the next ten years are calculated (Table 5). According to the results of the calculation, the annual water injection of the next ten years increases year by year. By the end of 2024, the annual water injection rate reaches $261.429 \mathrm{t} / \mathrm{d} \times 10^{4} \mathrm{t}$, and the average annual increase in water injection rate is $0.9206 \times 10^{4} \mathrm{t} / \mathrm{d}$. The prediction results have a great guiding significance for oil field water injection.

\section{Conclusions}

1. A method to predict reasonable water injection rate of $\mathrm{M}$ oilfield is presented in this paper. It consists of three parts. The first step is deriving equation to calculate reasonable injection-production rates by material balance equation. The second step is deducing formula to forecast water cut and oil production rate by relative empirical equation with production data. The last step is constructing an equation to calculate reasonable water injection rate with the above derived Eqs.

2. This method is applied in $\mathbf{M}$ oilfield to calculate relative development indexes of future 10 years. Result shows that by 2024 , the liquid production rate is $224.89 \times 10^{4} \mathrm{t} / \mathrm{a}$, and the water cut is $95.697 \%$, and the reasonable water injection rate is $261.43 \times 10^{4}$ t/a.

3. Material balance equation, oil production decline rule and water flooding characteristic curve are reasonably utilized in this paper. This method can be applied to other multilayer sandstone water drive reservoirs to determine reasonable water injection rate.

Open Access This article is distributed under the terms of the Creative Commons Attribution 4.0 International License (http:// creativecommons.org/licenses/by/4.0/), which permits unrestricted use, distribution, and reproduction in any medium, provided you give appropriate credit to the original author(s) and the source, provide a link to the Creative Commons license, and indicate if changes were made.

\section{References}

Ballin PR, Shirzadi S, Ziegel E (2012) Waterflood management based on well allocation factors for improved sweep efficiency: model based or data based? Soc Pet Eng. doi:10.2118/153912-MS

Bashiri A, Kasiri N (2011) Revisit material balance equation for naturally fractured reservoirs. Soc Pet Eng. doi:10.2118/150803MS

Buckwalter JF (1951) Selection of pressure for water flooding various reservoirs. American Petroleum Institute, Washington

Chambers B, Karra S, Mortimer L (1980) Use of type curve analysis in predicting the behaviour of a water-drive reservoir. Pet Soc Can. doi:10.2118/80-01-03

Chen Y (1985) Derivation of relationships of water drive curve. Acta Pet Sin 6(2):69-78

Chen Y (1986) Development of Fuyu fractured sandstone reservoirs by water injection. Soc Pet Eng. doi:10.2118/14843-MS

Cui C, Wu L, Song Z, Li N (2010) Method to determine reasonable injection-production ratio edge water reservoir research oil-gas field. Surf Eng 09:29-31

Dong J, Zhai Y, Yang J, Zhao C (1999) Determination of injectionproduction ratio size by type-curve analysis. Soc Pet Eng. doi:10. 2118/57320-MS

Frederick JL, Kelkar MG (2005) Decline curve analysis for solution gas drive reservoirs. Soc Pet Eng. doi:10.2118/94859-MS

Gao W, Peng C, Li Z (2000) A derivation method and percolation theory of water drive characteristic curves. Pet Explor Dev 27(5):56-60

Gulick KE et al (1998) Waterflooding heterogeneous reservoirs. An overview of industry experiences and practices. SPE 40044:1-7

Hou Y (2014) Inefficient circulation for determining reservoir and stripe recognition technology research. Technol Bus 9:151

Li K (2003) A decline curve analysis model based on fluid flow mechanisms. SPE 83470:1-10

Li H, Liu Z, Zhan L, Wang T (2015) Reasonable logistic cycle model in oilfield water injection, and the application of the injection-

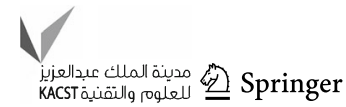


production ratio to determine. J Shengli Coll China Univ Pet 04:30-32

Luo C, Xu H (1999) Quantitative relationships between formation pressure level and injection-production ratio and water cut. J Xi'an Pet Inst 14(4):33-34

Olu O, Adebayo O, Femi A, Segun O (2014) Resolution of out of zone water injection in Okan field by use of material balance method. Soc Pet Eng. doi:10.2118/172417-MS

Orozco D, Aguilera R (2017) A material-balance equation for stresssensitive shale-gas-condensate reservoirs. Soc Pet Eng. doi:10. 2118/177260-PA

Paige RW, Murray LR, Martins JP, Marsh SM (1995) Optimising water injection performance. Soc Pet Eng. doi:10.2118/29774MS

Palsson B, Davies DR, Todd AC, Somerville JM (2003) Water injection optimized with statistical methods. Soc Pet Eng. doi:10. 2118/84048-MS

Qixin L, Yuzhuo W, Huanzhong D (1997) Relationship between reasonable injection-production ratio and pressure level in development area of Southern Saertu reservoir. Soc Pet Eng, Daqing oilfield. doi:10.2118/30852-PA

Rehman A, Peeran S, Beg DN (2015) Compact in-line bulk water removal technologies - a solution to the high water cut challenges. Soc Pet Eng. doi:10.2118/175272-MS
Shan W, Song K, Wenshuang GE, Min Y, Bo LV (2013) Use of function to determine water injection rate. Math Pract Theory $13: 122-129$

Shangguan Y, Zhao Q, Song J, An Z et al (2003) Reasonable injection allocation methods. Pet Geol Oilfield Dev Daqing 22(3):40-42

Sommerauer G, Zerbst C (2007) Rapid pressure support for champion SE reservoirs by multilayer fractured water injection. Soc Pet Eng. doi:10.2118/101017-PA

Wagn M, Shi C, Zhu W et al (2016) Identification and accurate description of preponderance flow path. Pet Geol Recovery Effic 23(1):79-84

Wang L (2013) Application research on water flooding law curve. China Pet Chem Stand Quality 03:132

Yu L, Feng J, Zhang S, Lian Z, Chang Y, Feng J, Yan J (2010) Research on development rules and strategies in the low R/P ratio of Tarim major sandstone reservoirs. Soc Pet Eng. doi:10. 2118/131333-MS

Zhao Y (2013) China research and application of suitable injectionproduction ratio. Pet Chem Stand Quality 1:81

Zhu J, Zhang Y, Zhu S (2015) Reasonable formation pressure maintenance level meeting the water flooding law of oil reservoirs. J Xi' an Shiyou Univ (Nat Sci Ed) 1:38-41+6 